AperTO - Archivio Istituzionale Open Access dell'Università di Torino

\title{
Gold catalyzed Heck-coupling of arenediazonium o-benzenedisulfonimides
}

\section{This is a pre print version of the following article:}

Original Citation:

Availability:

This version is available http://hdl.handle.net/2318/1657737

since 2018-01-16T15:13:15Z

Published version:

DOI:10.1039/C7OB02624B

Terms of use:

Open Access

Anyone can freely access the full text of works made available as "Open Access". Works made available under a Creative Commons license can be used according to the terms and conditions of said license. Use of all other works requires consent of the right holder (author or publisher) if not exempted from copyright protection by the applicable law. 


\section{Journal Name}

\section{ARTICLE}

\section{Gold Catalyzed Heck-Coupling of Arenediazonium o- Benzenedisulfonimides}

Received 00th January 20xx, Accepted 00th January 20xx

DOI: $10.1039 / \times 0 \times x 00000 x$

www.rsc.org/

\begin{abstract}
Margherita Barbero ${ }^{\mathrm{a}}$ and Stefano Dughera*a
Diazonium salts, and precisely arenediazonium o-benzenedisulfonimides, have been used for the first time as efficient electrophilic partners in gold catalyzed Heck-coupling reactions. The synthetic protocol was general, easy and gave the target products in satisfactory yields. Mechanistic insights revealed the fundamental roles of the anion of $o$-benzenedisulfonimide as an electron transfer agent which promotes a radical pathway that does not require the presence of photocatalysts or external oxidants
\end{abstract}

\section{Introduction}

Gold catalysis is considered a fundamental topic in organic synthesis with several applications in total syntheses of complex systems, asymmetric syntheses, $\mathrm{C}-\mathrm{H}$ activation reactions and $\mathrm{C}$ C bond formation. ${ }^{1 a-d}$ The high importance of gold catalysis is attributable to some peculiar qualities of gold which include good commercial availability, remarkable stability, functional group and oxygen tolerance, tunability, minimal use of additive and excellent chemoselectivity. ${ }^{1 e, f}$ Many of the investigations into the catalytic reactivity of gold make use of the propensity of cationic $\mathrm{Au}$ (I) complexes to activate alkynes towards nucleophilic addition due to their large $\pi$-acidic character (alkynophilicity). ${ }^{1 \mathrm{~g}}$ Extensive studies in this area have been performed and have found that a wide set of nucleophiles ( $N$, $\mathrm{S}, \mathrm{O}$ and $\mathrm{C}$ nucleophiles) can be added to alkynes in an intramolecular or intermolecular fashion, resulting in the formation of new C-C or C-heteroatom bonds. ${ }^{\text {h, }, \mathrm{i}}$

In recent years several other gold-catalyzed $\mathrm{C}-\mathrm{C}$ bond-forming reactions have been reported. ${ }^{2}$ While focusing our attention on "classical" cross-coupling reactions, it must be stressed that as $\mathrm{Au}(\mathrm{I})$ has the same $\mathrm{d}^{10}$ configuration as $\mathrm{Pd}(0)$ and $\mathrm{Cu}(\mathrm{I})$, meaning that it is able to catalyze reactions typically promoted by $\mathrm{Pd}(0) \cdot{ }^{3} \mathrm{~A}$ number of $\mathrm{Au}$ (I) (or Au (III) in Suzuki coupling ${ }^{4 a}$ ) complexes have successfully been employed for the Suzuki, ${ }^{4}$ Sonogashira ${ }^{5}$, Stille ${ }^{6}$ and Hiyama ${ }^{7}$ couplings in high yields and with high selectivity. It is worth noting that strong oxidants were normally required in order to facilitate the $\mathrm{Au}$ (I)/Au (IIII) transition in the catalytic cycle.

Arenediazonium salts have been widely used as electrophilic partners in palladium-catalysed cross coupling reactions, including Mizoroki-Heck reactions, Suzuki-Miyaura reactions,

a. Dipartimento di Chimica, Università di Torino, C.so Massimo d'Azeglio 48, 10125 Torino, Italy.E-mail:, stefano.dughera@unito.it

Electronic Supplementary Information (ESI) available: [Physical and spectroscopica data of compounds 4-7; NMR spectra of compounds 4-7; references]. See DOI: $10.1039 / x 0 x x 00000 x$ and Stille couplings, and so they have become an effective alternative to aryl halides. ${ }^{8}$ The use of diazonium salts has some general advantages: they are more reactive, due to the fact that the diazonium group is a better nucleofuge than halide or triflate; they are easily available from anilines, no base or additional ligands are generally needed; they require mild reaction conditions and short reaction times, and the coupling products are generally obtained in high yields.

Interestingly, arenediazonium salts have been recently used as electrophilic reactants in several $\mathrm{Au}$ (I) catalyzed arylation reactions $^{9}$ and cross-coupling reactions (i.e. Suzuki, ${ }^{10}$ In fact, their capacity to undergo to a single-electron reduction under visible light and in the presence of photosensitizers means that they provide aryl radicals which give sequential oxidative additions onto $\mathrm{Au}$ (I) species. The subsequent reductive elimination from the resulting $\mathrm{Au}$ (III) complexes, produces the desired coupling adducts and regenerates the $\mathrm{Au}$ (I) catalyst.

If gold catalyzed Suzuki and Sonogashira reactions have now generally become well-established protocols, on the contrary, gold catalyzed Heck reactions are a topic that has so far scarcely been studied. ${ }^{13}$ In particular, to the best of our knowledge, arenediazonium salts have never been used as electrophilic partners in this reaction.

Some of our research has resulted in a large family of dry diazonium salts, the arenediazonium $o$-benzenedisulfonimides 1 (Fig. 1). ${ }^{14 a}$

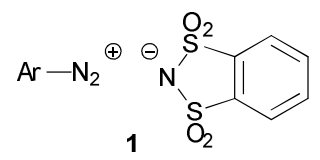

Fig 1 Arenediazonium o-benzenedisulfonimides 1

The properties of these compounds mean that they have great potential in numerous synthetic applications. They are easy to Sonogashira ${ }^{11}$ coupling), usually under fotoredox conditions. ${ }^{12}$ 
prepare and isolate, they are extremely stable, and they can be stored for an unlimited time. Moreover, they react easily both in water and in organic solvents, and $o$-benzenedisulfonimide (2; Fig 2) can easily be recovered and reused at the end of the reactions.

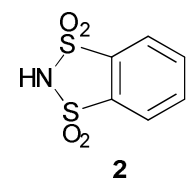

Fig 2 o-Benzenedisulfonimide (2)

Exploration into the synthetic potential of these salts, has led to them giving excellent results, in palladium catalysed coupling reactions, namely Heck reactions, ${ }^{14 b}$ Stille, ${ }^{14 c, d}$ Suzuki, ${ }^{14 d}$ Negishi ${ }^{14 e}$ and Sonogashira ${ }^{14 f}$ couplings and in couplings with organoindium derivatives. ${ }^{14 \mathrm{~g}, \mathrm{~h}}$

The ever growing use of gold as a catalyst in organic synthesis, has driven us to enter this fascinanting field. We herein described the reactivity of said salts 1 as partners in $A u(I)$ catalyzed Heck reactions (Scheme 1).

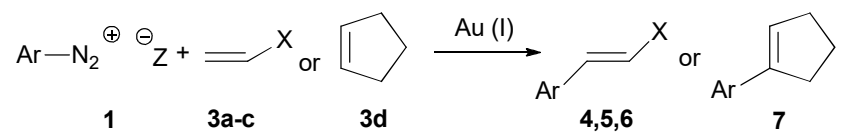

$\mathrm{X}$ in $\mathbf{3 a}, \mathbf{4}=\mathrm{CHO} ; \mathbf{3 b}, \mathbf{5}=\mathrm{COOEt} ; \mathbf{4 c}, \mathbf{6}=\mathrm{Ph}$

$\mathrm{Au}(\mathrm{I})=\mathrm{Ph}_{3} \mathrm{PAuCl}$ or $\mathrm{Ph}_{3} \mathrm{PAuNTf}_{2}$

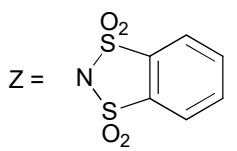

Scheme $1 \mathrm{Au}$ (I) catalyzed Heck reaction between arenediazonium $\boldsymbol{o}$-benzenedisulfonimides $\mathbf{1}$ and olefines 3a-d

\section{Results and discussion}

Initially, the model reaction between acrylaldehyde (3a) and 4nitrobenzenediazonium o-benzenedisulfonimide (1a) was carried out in the presence of [bis(trifluoromethanesulfonyl)imidate] (triphenylphosphine) gold as the catalyst in order to optimize the reaction conditions, as reported in Table 1 (entries 1-19). Various conditions were tested, solvents and/or temperatures were changed and bases and/or photocatalyst were added. The desired coupling product, 4-nitrocinnamaldehyde (4a), was formed under heating at $50^{\circ} \mathrm{C}$ in $\mathrm{MeCN}$ or EtOH. It is worthing note that only $\mathrm{CaCO}_{3}$ could be used as a base in EtOH (Table 1, entry 10), while various bases were compatible in MeCN (Table 1, entries 13, 15-19). However the yields were poor and unsatisfactory. It must be stressed that, interestingly, no photocatalyst was necessary (Table 1, entry 18) and the reaction also occurred in the dark (Table 1, entry 19).
So, we decided to change the gold catalyst and we carried out the reaction in the presence of chloro(triphenylphosphine)gold (Table 1, entries 20-30). We tested various solvents and bases at different temperatures and, to our delight, optimal conditions were found: heating at $35^{\circ} \mathrm{C}$ with $\mathrm{MeCN}$ as a solvent and $\mathrm{CaCO}_{3}$ as the base (Table 1 , entry 23 ). A photocatalyst was also unnecessary in this case (Table 1 , entry 25 ) and the reaction also occurred in the dark (Table 1 , entry 26). The target 4 a was easily separated, by means of a chromatographic column from three by-products, shown in Figure 3, namely $\mathrm{N}$-(4-nitrophenyl)o-benzenedisulfonimide (8), nitrobenzene (9) and 4,4'dinitrobiphenyl (10).

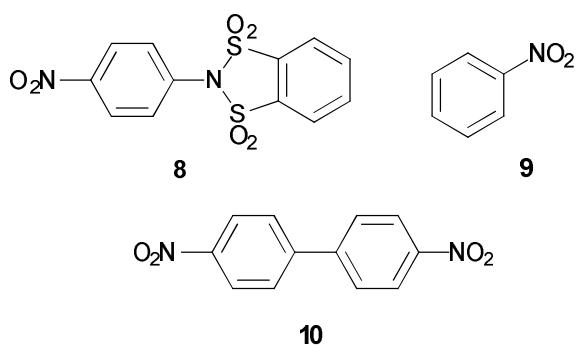

Fig 3 By-products

The high yield and simplicity of the procedure encouraged us to explore the generality and scope of this reaction further, using different salts $\mathbf{1}$ and olefines $\mathbf{3 a - d}$ (Scheme 1 ). The results are shown in Table 2. The Heck couplings of various salts $1 \mathbf{1 a}-\mathbf{j}$ in $\mathrm{MeCN}$, in the presence of chloro(triphenylphosphine)gold as the catalyst and $\mathrm{CaCO}_{3}$ as the base, gave the corresponding adducts 4-7 in excellent yields, under simple and mild reaction conditions. The reaction was chemoselective; no traces of disubstituted adducts were detected in the reactions of diazonium salts containing a bromine or iodine atom, which could potentially react in the same way as the diazonium group (Table 2, entries 9-12, 26). The reaction was not affected by electronic effects; adducts 4 were obtained in satisfactory yields from salts 1 bearing either electron-donating or electronwithdrawing groups. On the other hand, the influence of steric hindrance was evident: reactions of salts 1 bearing ortho substituents failed (Table 2, entries 17, 19, 20, 21, 23, 24, 25, 27,28 ) with the only exception being those carried out with $\mathbf{3 b}$ (Table 2, entries 18, 22, 26). Moreover, the reactions of heteroarene diazonium o-benzenedisulfonimides $\mathbf{1} \mathbf{i}$-j (Table 2, entries 33,34 ), with the only exception of $\mathbf{1 h}$ (Table 2 , entries 29-32) also failed. Finally, it is interesting to highlight that the reactions between $\mathbf{1}$ and $\mathbf{3 d}$ were highly regioselective: only traces of possible 3 -arylcyclopentenes were detected (Table 2 , entries $4,8,12,16,32$ ).

It was possible to recover 0 -benzenedisulfonimide (2) in about $80 \%$ yields from all the reactions described above. 2 was recycled for the preparation of further salts $\mathbf{1}$, which is beneficial from economic and ecological point of view. 
Table 1 Trial reactions between acrilaldehyde (3a) and 4-nitrobenzenediazonium o-benzenedisulfonimide (1a)

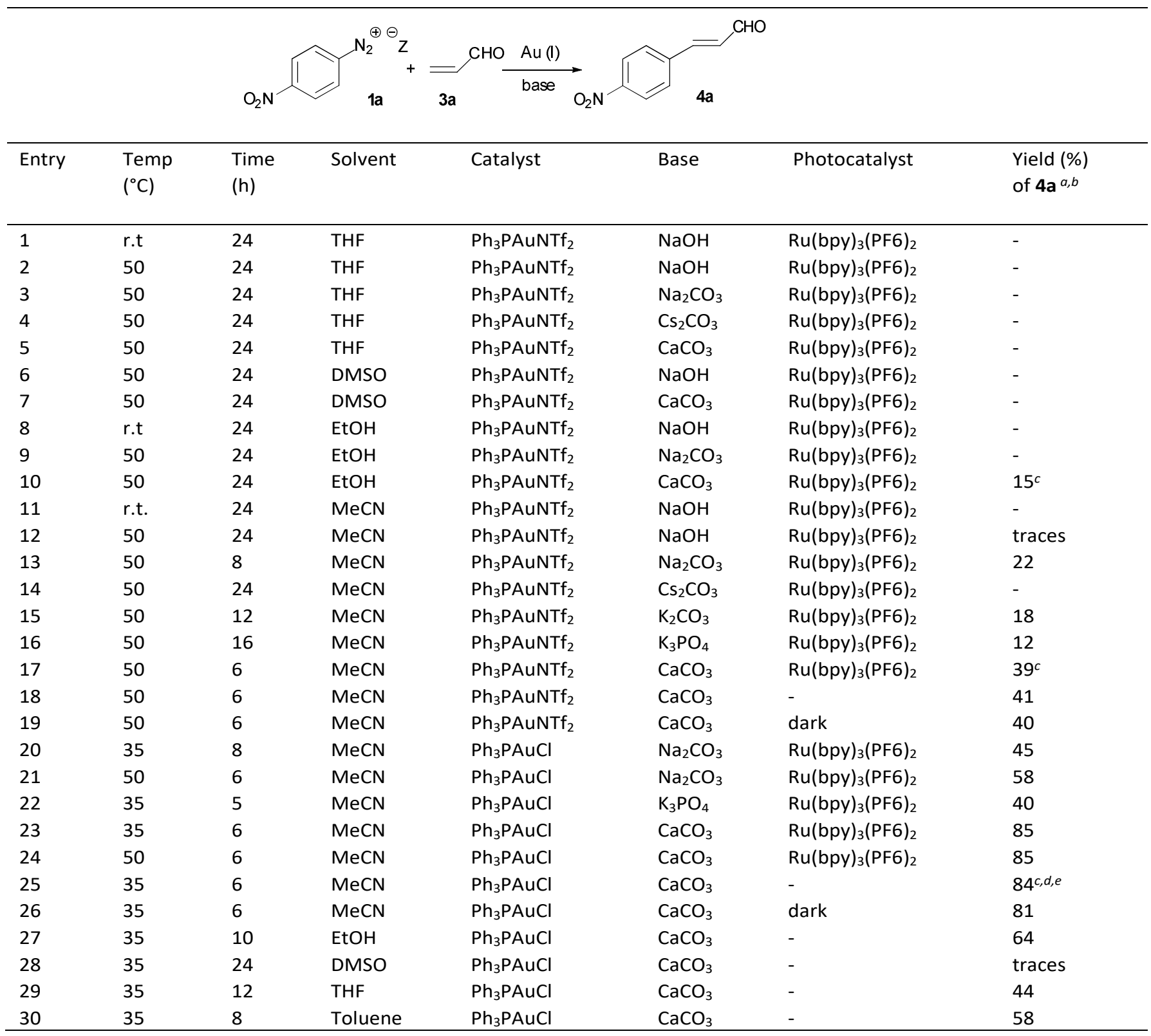

${ }^{a}$ All the reactions were carried out heating at $35^{\circ} \mathrm{C}$, under nitrogen flow, with $1 \mathrm{mmol}$ of $\mathbf{1 a}, 1.5 \mathrm{mmol}$ of $\mathbf{3 a}, 5 \mathrm{~mol} \%$ of Au catalysts, $1 \mathrm{mmol}$ of various bases and $5 \mathrm{~mol} \%$ of photocactalyst ${ }^{b}$ Yields refer to pure and isolated $4 \mathrm{a}$, purified on a silica gel chromatography column. The eluent was petroleum ether/diethyl ether $(9: 1) .^{c}$ Higher amount of base or Au catalysts oh higher temperatures does not lead to a yield increase. ${ }^{d}$ At room temperature the yield of 4 a was remarkably lower $(45 \%)$. ${ }^{e}$ When the reaction was carried out in the presence of 1,3-dinitrobenzene $(1 \mathrm{mmol}, 170 \mathrm{mg})$ no $4 \mathrm{a}$ was formed 
Table 2 Gold catalyzed reactions between $\mathbf{1 a - j}$ and $\mathbf{3 a - d}$

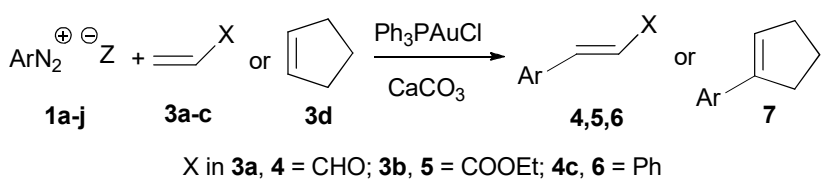

\begin{tabular}{|c|c|c|c|c|}
\hline Entry & Ar in 1 & 3 & Time (h) & Products 4-7 and yields $(\%)^{a, b}$ \\
\hline 1 & $1 \mathrm{a} ; 4-\mathrm{NO}_{2} \mathrm{C}_{6} \mathrm{H}_{4}$ & 3a; $\mathrm{X}=\mathrm{CHO}$ & 6 & $4 a ; 84^{c, d}$ \\
\hline 2 & $1 a$ & 3b; $X=$ COOEt & 4 & $5 a ; 87$ \\
\hline 3 & $1 a$ & $3 c ; X=\mathrm{C}_{6} \mathrm{H}_{5}$ & 3.5 & 6a; 91 \\
\hline 4 & $1 a$ & 3d; $X=$ cyclopentyl & 7 & $7 a ; 67$ \\
\hline 5 & 1b; $4-\mathrm{MeC}_{6} \mathrm{H}_{4}$ & $3 a$ & 8 & $\mathbf{4 b} ; 72^{e, f}$ \\
\hline 6 & $1 b$ & $3 \mathbf{b}$ & 7.5 & 5b; 68 \\
\hline 7 & $1 b$ & $3 c$ & 9 & 6b; 75 \\
\hline 8 & $1 b$ & 3d & 12 & $7 b ; 63$ \\
\hline 9 & 1c; $4-\mathrm{BrC}_{6} \mathrm{H}_{4}$ & $3 a$ & 6.5 & 4c; 81 \\
\hline 10 & $1 c$ & $3 \mathbf{b}$ & 3.5 & 5c; 90 \\
\hline 11 & 1c & $3 c$ & 5 & $6 c ; 82$ \\
\hline 12 & $1 c$ & 3d & 7.5 & 7c; 79 \\
\hline 13 & $1 d ; 3-\mathrm{NO}_{2} \mathrm{C}_{6} \mathrm{H}_{4}$ & $3 a$ & 4.5 & 4d; 82 \\
\hline 14 & $1 d$ & $3 \mathbf{b}$ & 6 & $5 d ; 87$ \\
\hline 15 & $1 d$ & $3 c$ & 5 & 6d; 90 \\
\hline 16 & $1 d$ & $3 d$ & 8 & $7 d ; 69$ \\
\hline 17 & $1 \mathrm{e} ; 2-\mathrm{NO}_{2} \mathrm{C}_{6} \mathrm{H}_{4}$ & $3 a$ & 24 & - \\
\hline 18 & $1 e$ & $3 b$ & 8 & $5 e ; 32^{g}$ \\
\hline 19 & $1 e$ & $3 c$ & 24 & $\mathbf{6 e}$; traces \\
\hline 20 & $1 e$ & $3 d$ & 24 & - \\
\hline 21 & 1f; $2-\mathrm{MeC}_{6} \mathrm{H}_{4}$ & $3 a$ & 24 & - \\
\hline 22 & $1 f$ & $3 \mathbf{b}$ & 10 & $\mathbf{5 f} ; 3^{g}$ \\
\hline 23 & $1 f$ & $3 c$ & 24 & 6f; traces \\
\hline 24 & $1 f$ & $3 d$ & 24 & - \\
\hline 25 & $1 \mathrm{~g} ; 2-\mathrm{IC}_{6} \mathrm{H}_{4}$ & $3 a$ & 24 & - \\
\hline 26 & $1 \mathrm{~g}$ & $3 b$ & 10 & $5 g ; 28^{g}$ \\
\hline 27 & $1 \mathrm{~g}$ & $3 c$ & 24 & - \\
\hline 28 & $1 \mathrm{~g}$ & $3 d$ & 24 & - \\
\hline 29 & 1h; & $3 a$ & 4.5 & $4 h ; 86$ \\
\hline 30 & $1 \mathrm{~h}$ & $3 b$ & 3.5 & $5 h ; 91$ \\
\hline 31 & $1 \mathrm{~h}$ & $3 c$ & 5 & 6h; 84 \\
\hline 32 & 1h & $3 d$ & 8 & 7h; 64 \\
\hline 33 & $1 \mathbf{i} ;$ & $3 b$ & 24 & - \\
\hline 34 & $1 \mathrm{j}$; & $3 b$ & 24 & - \\
\hline
\end{tabular}

a All the reactions were performed in $\mathrm{MeCN}$ at $35^{\circ} \mathrm{C}$ under nitrogen flow in the presence of $\mathrm{CaCO}_{3}(1 \mathrm{mmol})$ and $\mathrm{Ph}_{3} \mathrm{PAuCl}(5$ mol\%). The 1 ( $1 \mathrm{mmol}): 3$ ratio was 1:1.5. ${ }^{b}$ Yields refer to pure and isolated 4-7, purified from the by-products on a silica gel 
chromatography column. ${ }^{c}$ The reaction was carried out in EtOH using 4-nitrobenzenediazonium tetrafluoroborate (1 mmol) instead of $\mathbf{1 a}$. The yield of $\mathbf{4 a}$ was $76 \%{ }^{d}$ The reaction was carried out in MeCN using 4-nitrobenzenediazonium tetrafluoroborate $(1 \mathrm{mmol})$ instead of $1 \mathrm{a}$. The yield of $4 \mathrm{a}$ was $12 \%$. ${ }^{e}$ The reaction was carried out in EtOH using 4-tolyldiazonium tetrafluoroborate $(1 \mathrm{mmol})$ instead of $\mathbf{1 b}$. The yield of $\mathbf{4 b}$ was $25 \% .{ }^{f}$ The reaction was carried out in MeCN using 4- tolyldiazonium tetrafluoroborate $(1 \mathrm{mmol})$ instead of $\mathbf{1 b}$. No $\mathbf{4 b}$ was formed. ${ }^{g}$ The reaction was performed heating at $50^{\circ} \mathrm{C}$ in the presence of $\mathrm{CaCO}_{3}(1.5 \mathrm{mmol})$. The $1(1 \mathrm{mmol}): \mathbf{3}$ ratio was 1:2.

The copious and homogeneous results collected provide a good basis for some comments on the reaction mechanism. The first and fundamental fact is that this reaction also occurred in the dark and without any photocatalyst. S. Schin ${ }^{15}$ and coworkers have recently reported an interesting study concerning the cross-coupling of vinyl gold derivatives with diazonium salts under photoredox or thermal conditions. In fact, they found that the reaction can run in the dark under thermal conditons, where arenediazionium tetrafluoroborate decomposed under heating at $60^{\circ} \mathrm{C}$ In $\mathrm{MeOH}$, forming aryl radicals which oxidize the $\mathrm{Au}(\mathrm{I})$ catalyst, allowing the coupling reaction to occur.

In the light of this, we believe that the reaction mechanism of this Heck coupling may be similar to that proposed by Schin. First, a reaction was carried out between $1 \mathbf{a}$ and $3 a$ in the presence of 1,3-dinitrobenzene, an excellent electron acceptor. This reaction failed and so we confirmed its homolytic course by means of this known diagnostic test (Table 1 , entry 25 note e). Under Schin conditions, the formations of aryl radicals from arenediazonium tetrafluoroborate was possible in $\mathrm{MeOH}$ at $60^{\circ} \mathrm{C}$. In fact, a thorough study on this topic which proves that the formation of aryl radicals from arenediazonium tetrafluoroborates is the result of an electron transferhomolysis mechanism, promoted by $\mathrm{EtOH}$ and followed by dediazoniation, has been reported in the literature. ${ }^{16}$ Moreover, it is also known from the literature that this thermal reduction of arenediazonium tetrafluoroborates in alcoholic solvents, producing free-radicals, is favoured in the order of $\mathrm{p}$ $\mathrm{MeO}>\mathrm{p}-\mathrm{NO} 2, \mathrm{p}-\mathrm{Br}>\mathrm{p}-\mathrm{CH}_{3}>\mathrm{H}$ group in the diazonium salts. ${ }^{17}$ Accordingly, the reaction carried out with $3 \mathbf{a}$ and 4tolyldiazonium tetrafluoroborate carried out in $\mathrm{EtOH}$ furnished 4b in low yields (Table 2, entry 5 note e), while good results were achieved with 4-nitrobenzenediazonium tetrafluoroborate (Table 2, entry 1 note c). On the other hand, the same reactions, carried out in $\mathrm{MeCN}$ gave low yields of target 4a (12\%; Table 2, entry 1, note d), whilst no $\mathbf{4 b}$ formed (Table 2, entry 5 , note $\mathrm{f}$ ).

It is interesting to note that various solvents were suitable for use with salts 1 (Table 1 , entries 20,27-30) and that the yields of $\mathbf{4 a}$ and $\mathbf{4 b}$ in the reactions carried out in MeCN with $\mathbf{1 a}$ and 1b were both good and almost the same (Table 2, entries 1,5 ). In two our previous papers, more precisely in the bromodediazotation $^{18 a}$ and Sandmeyer reaction ${ }^{18 b}$ of $\mathbf{1}$, we reported that the anion of $\mathbf{2}$ would act as an electron donor toward the arenediazonium cation, most likely giving rise to the electron transfer complex 11 (Fig. 4) where the partner of the aryldiazenyl radical is highly resonance stabilized (11a, 11b).

The generation of this complex $\mathbf{1 1}$ occurred even at room temperature, in a variety of solvents and regardless of the type of aromatic ring-bonded substituents. ${ }^{18 a, b}$ In the light of this, we believe that the formation of $\mathbf{1 1}$ may explain the homolitic course (partial, however) of this reaction as shown in Scheme 2.<smiles>O=S1(=O)N=N[Al]c2ccccc21</smiles>

Fig 4 Electron transfer complex 11

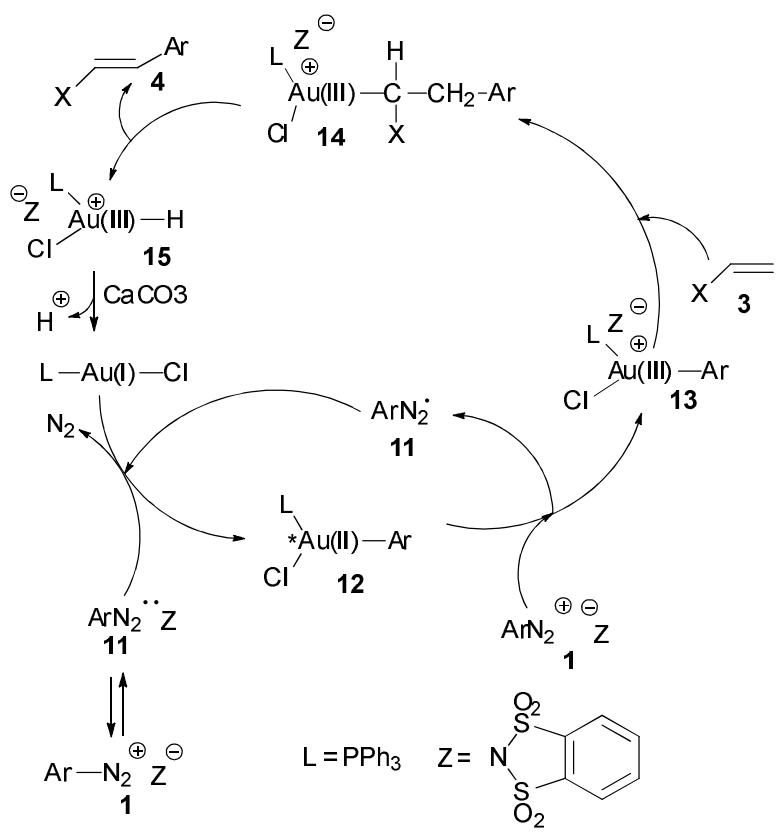

Scheme 2 Hypothesized mechanism

In particular, we postulate that the complex $\mathbf{1 1}$ interacts with the $\mathrm{Au}$ (I) catalyst, transferring on it an aryl radical; the $\mathrm{Au}(\mathrm{II})$ complex $\mathbf{1 2}$ forms. A further oxidation of 12, most likely due to an electron donated by $\mathbf{1}$, gives the $\mathrm{Au}(\mathrm{III})$ complex $\mathbf{1 3}$ and other diazenyl radicals $\mathbf{1 1}$ which contribute to oxidizing the $\mathrm{Au}$ (I) catalyst. It is interesting to note that this radical chain, triggered by $\mathrm{Au}(\mathrm{I})$ catalyst interaction with $\mathbf{1 1}$, allows the oxidation of the $\mathrm{Au}$ (I) catalyst to $\mathrm{Au}$ (III) to occur, without the participation of photocatalysts or external oxidants. At this point, the Au (III) complex 13 is ready to undergo the typical reactions occurring in the Heck coupling catalytic cycle. ${ }^{19}$ First, the insertion reaction with 3 leads to $\mathrm{Au}$ (III) complex $\mathbf{1 4}$ and then a $\beta-\mathrm{H}$ 
elimination reaction produces target $\mathbf{4}$ and $\mathrm{Au}$ (III) complex 15. The reductive elimination reaction of the latter, in the presence of $\mathrm{CaCO}_{3}$, restores the starting catalyst $\mathrm{Ph}_{3} \mathrm{PAuCl}$.

As shown above (Table 1), catalyst type was crucial to the success of the reaction. In fact, the reaction carried out in the presence of [bis(trifluoromethanesulfonyl)imidate] (triphenylphosphine) gold led to unsatisfactory results. It is likely that the strong electron withdrawing group bis(trifluoromethanesulfonyl)imidate destabilizes intermediates 12-15, making their formation difficult. Finally, we believe that the by-product $\mathbf{1 0}$ shown in Figure 3, may be a clue to this radical mechanism. It may derive from the coupling of some of the radicals that form in the reaction pathway. Further theoretical investigations into mechanistic aspects of this coupling reaction are currently underway.

\section{Conclusions}

We have herein proposed a mild, easy and efficient gold catalyzed Heck coupling of arenediazonium obenzenedisulfonimides 1 . The target products 4-7 were generally obtained in satisfactory yields ( 23 positive examples, $73 \%$ average yield). It is worth noting the interesting role that the $o$-benzenedisulfonimide anion plays as an electron transfer agent in enabling a radical pathway that does not require the presence of photocatalysts or external oxidants. To the best of our knowledge, arenediazonium salts have been used as partners in gold catalyzed Heck reaction for the first time in this paper.

\section{Experimental}

\section{General}

All the reactions were carried out in oven dried glassware and under a nitrogen flow. Analytical grade reagents and solvents were used and reactions were monitored by GC, GC-MS and TLC. Column chromatography and TLC were performed on Merck silica gel 60 (70-230 mesh ASTM) and GF 254, respectively. Petroleum ether refers to the fraction boiling in the range $40-70{ }^{\circ} \mathrm{C}$. Room temperature is $20^{\circ} \mathrm{C}$. Mass spectra were recorded on an HP 5989B mass selective detector connected to an HP 5890 GC with a methyl silicone capillary column. ${ }^{1} \mathrm{H}$ NMR and ${ }^{13} \mathrm{C}$ NMR spectra were recorded on a Brucker Avance 200 spectrometer at 200 and $50 \mathrm{MHz}$ respectively. IR spectra were recorded on an IR Perkin-Elmer UATR-two spectrometer. Dry arenediazonium $O$ benzenedisulfonimides $\mathbf{1}$ were prepared as described previously by us. ${ }^{14 a}$ The crude salts 1 were virtually pure (by ${ }^{1} \mathrm{H}$ NMR spectroscopy) and were used in subsequent reactions without further crystallization. 4-Tolyldiazonium and 4nitrobenzenediazonium tetrafluoroborate were prepared as reported in the literature. ${ }^{20}$ All the other reagents were purchased from Sigma-Aldrich or Alfa-Aesar. Structures and purity of all the products obtained in this research were confirmed by their spectral (NMR, MS and IR) and physical data (reported in Supplementary Information), substantially identical to those reported in the literature. Yields of the pure (GC, GC-MS, TLC and NMR) isolated compounds 4-7 are collected in Table 2. Satisfactory microanalyses were obtained for all new compounds.

\section{4-Nitrocinnamaldehyde (4a): representative procedure for the gold catalyzed Heck reactions}

In a oven-dried flask and under nitrogen flow, first anhydrous $\mathrm{CaCO}_{3}(100 \mathrm{mg}, 1 \mathrm{mmol}$ ) and then 4-nitrobenzenediazonium obenzenedisulfonimide $(\mathbf{1 a}, 370 \mathrm{mg}, 1 \mathrm{mmol})$ was added to a solution of acrolein (3a, $90 \mathrm{mg}, 1.5 \mathrm{mmol}$ ) and chloro(triphenylphosphine)gold (I) (25 mg, $0.05 \mathrm{mmol}, 5 \mathrm{~mol} \%$ ) in $\mathrm{MeCN}(5 \mathrm{ml})$. The resulting mixture was stirred at $35^{\circ} \mathrm{C}$ for 6 $h$; the completion of the reaction was confirmed by the absence of azo coupling with 2-naphthol. Then, the reaction mixture was poured into diethyl ether/water $(100 \mathrm{~mL}, 1: 1)$. The aqueous layer was separated and extracted with diethyl ether $(50 \mathrm{~mL})$. The combined organic extracts were washed with water (50 $\mathrm{mL}$ ), dried with $\mathrm{Na}_{2} \mathrm{SO}_{4}$ and evaporated under reduced pressure. GC-MS analyses of the crude residue showed 4nitrocinnamaldehyde (4a, MS (EI): $\left.m / z=177[\mathrm{M}]^{+}\right)$as the major product, besides traces of 4,4'-dinitrobiphenyl (10), MS (EI) $\mathrm{m} / \mathrm{z}$ $=244[\mathrm{M}]^{+}$, nitrobenzene (9), MS (EI) $\mathrm{m} / z=123[\mathrm{M}]^{+}, \mathrm{N}-(4-$ nitrophenyl)-o-benzenedisulfonimide (8) MS (EI) $m / z=340$ [M] ${ }^{+}$ The crude residue was purified on a short column, eluting with petroleum ether/diethyl ether (9:1). The only isolated product was the title compound (4a, $150 \mathrm{mg}, 84 \%$ yield). The aqueous layer and aqueous washings were collected and evaporated under reduced pressure. The tarry residue was passed through a column of Dowex HCR-W2 ion exchange resin $(1.6 \mathrm{~g} / 1 \mathrm{~g}$ of product), eluting with water (about $50 \mathrm{~mL}$ ). After removal of water under reduced pressure, virtually pure $\left({ }^{1} \mathrm{H} \mathrm{NMR}\right) \mathrm{O}^{-}$ benzenedisulfonimide (2) was recovered (198 mg, 90\% yield; mp $192-194^{\circ} \mathrm{C}$. Lit. $\left.{ }^{14 a} 190-193^{\circ} \mathrm{C}\right)$.

\section{Conflicts of interest}

There are no conflicts to declare.

\section{Acknowledgements}

This work has been supported by the University of Torino and the Ministero dell'Università e della Ricerca.

\section{References}

1 a) S. A. Shahzad, M. A. Sajid, Z. A. Khan and D. CansecoGonzalez, Synth. Comm., 2017, 47, 735; b) R. Dorel and A. M. Echavarren, Chem. Rev., 2015, 115, 9028; c) Z. Li, C. Brouwer and C. He, Chem. Rev., 2008, 108, 3239; d) A. S. K. Hashmi, Chem. Rev., 2007, 107, 3180; e) A. Arcadi and S. Di Giuseppe, Curr. Org. Chem., 2004, 8, 795; f) D. J. Gorin and F. J. Toste, Nature, 2007, 446, 395; g) D. J. Gorin, B. D. Sherry and F. J. Toste, Chem. Rev., 2008, 108, 3351; g) D. V. Vidhani, J. W. Cran, M. E. Krafft and I. V. Alabugin, Org. Biomol. Chem., 2013, 11,1624; h) A. S. K. Hashmi, Gold Bull., 2003, 36, 3; i) W. 
Debrouwer, T. S. Heugebaert, B. I. Roman and C. V. Stevens, Adv. Synth. Catal., 2015, 357, 2975.

2 a) A. S. K. Kashmi, L. Schwarz, J.-H. Choi and T. M. Frost, Angew. Chem. Int. Ed., 2000, 39, 2285; b) H. Huang, Y. Zhou and H. Liu, Beilstein J. Org. Chem., 2011, 7, 897; c) H. Miyamura, A. Suzuki, T. Yasukawa and S. Kobayashi, Adv. Synth. Catal., 2015, 357, 3815; d) P. Guo, Catal. Commun., 2015, 68, 58.

3 a) H. A. Wegner and M. Auzias, Angew. Chem. Int. Ed., 2011 50, 8236; c) M. Livendahl and A. M. Echavarren, Chim. OggiChem. Today, 2012, 30, 19; d) P. Garcia, M. Malacria, C. Aubert, V. Gandon, and L. Fensterbank, ChemCatChem, 2010, 2, 493; e) O. Nieto Faza and C. Silva Lopez, J. Org. Chem., 2013, 78, 4929 .

4 a) C. González-Arellano, A. Corma, M. Iglesias and F. Sánchez, J. Catal., 2006, 238, 497; b) J. Han, Y. Liu and Rong Guo, J. Am. Chem. Soc., 2009, 131, 2060; c) M. Hofer, A. Genoux, R. Kumar and C. Nevado, Angew. Chem. Int. Ed., 2017, 56, 1021; d) N. Dwadnia, J. Roger, N. Pirio, H. Cattey, R. Ben Salem and J.-C. Hierso, Chem. Asian J., 2017, 12, 459; e) M. D. Levin and F. D. Toste, Angew. Chem. Int. Ed. 2014, 53, 6211.

5 a) A. Corma, R. Juarez, M. Boronat, F. Sanchez, M. Iglesias and H. Garcia, Chem. Commun., 2011, 47, 1446; J. Lin, H. Abroshan, C. Liu, M. Zhu, G. Li and M. Haruta, J. Catal., 2015, 330, 354; c) G. Li, D. Jiang, C. Liu, C. Yu and R. Jin, J. Catal., 2013, 306, 177; d) T. Lauterbach, M. Livendahl, A. Rosellon, P. Espinet and A. M. Echavarren, Org. Lett., 2010, 12, 3006; e) M. B. Nielsen, Synthesis, 2016, 48, 2732.

6 J. delPozo, D. Carrasco, M. H. Perez-Temprano, M. GarciaMelchor, R. Alvarez, J. A. Casares and P. Espinet, Angew. Chem. Int. Ed. 2013, 52, 2189 -2193.

7 W. E. Brenzovich, J.-F. Brazeau and F. Dean Toste, Org. Lett., 2010, 12, 4728.

8 a) A. Roglans, A. Pia-Quintana, M. Moreno-Mañas, Chem. Rev., 2006, 106, 4622; b) F.-X. Felpin, L. Nassar-Hardy, F. Le Callonnec, E. Fouquet, Tetrahedron, 2011, 67, 2815; (c) J. G. Taylor, A. V. Moro, C. R. D. Correia, Eur. J. Org. Chem., 2011, 1403.

9 a) Z. Xia, O. Khaled, V. Mouries-Mansuy, C. Ollivier and L. Fensterbank, J. Org. Chem., 2016, 81, 7182; b) B. Alcaide, P. Almendros, E. Busto and C. Lazaro-Milla, J. Org. Chem., 2017, 82, 2177; c) H. Peng, R. Cai, C. Xu, H. Chen and X. Shi, Chem. Sci., 2016, 7, 6190; d) V. Gauchot, D. R. Sutherland and A.-L. Lee, Chem. Sci., 2017, 8, 2885-2889; e) M. O. Akram, P. S. Mali and N. T. Patil, Org. Lett., 2017, 19, 3075.

10 a) S. Witzel, J. Xie, M. Rudolph and A. S. K. Hashmi, Adv. Synth Catal., 2017, 359, 1522; b) V. Gauchot and A.-L. Lee, Chem. Commun., 2016, 52, 10163; d) T. Cornilleau, P. Hermange and E. Fouquet, Chem. Commun., 2016, 52, 10040

11 a) R. Cai, M. Lu, E. Y. Aguilera, Y. Xi, N. G. Akhmedov, J. L. Petersen, H. Chen and X. Shi, Angew. Chem. Int. Ed., 2015, 54, 8772; b) B. Panda and T. K. Sarkar, Chem. Commun., 2010, 46, 3131.

12 a) B. Sahoo, M. N. Hopkinson and F. Glorius, J. Am. Chem. Soc., 2013, 135, 5505; b) X.-Z. Shu, M. Zhang, Y. He, H. Frei and F. D. Toste, J. Am. Chem. Soc., 2014, 136, 5844; c) B. Dong, H. Peng, S. E. Motika and X. Shi, Chem. Eur. J., 2017, 000, 000; d) M. Zhang, C. Zhu and L.-W. Ye, Synthesis, 2017, 49, 1150.

13 a) K.-J. Shi, C.-H. Shu, C.-X. Wang, X.-Y. Wu, H. Tian and P.-N Liu, Org. Lett., 2017, 19, 2801; b) J. Xie, J. Li, V. Weingand, M. Rudolph and A. S. K. Hashmi, Chem. Eur. J., 2016, 22, 12646; c) H. M. Song, B. A. Moosa and N. M. Khashab, J. Mater. Chem., 2012, 22, 15953; d) M. Nasrollahzadeh and A. Banaei, Tetrahedron Lett., 2015, 56, 500; e) K. E. Roth and S. A. Blum, Organometallics, 2011, 30, 4811.

14 a) M. Barbero, M. Crisma, I. Degani, R. Fochi and P. Perracino, Synthesis, 1998, 8, 1171; b) E. Artuso, M. Barbero, I. Degani, S. Dughera and R. Fochi, Tetrahedron, 2006, 62, 3146; c) S.
Dughera, Synthesis, 2006, 7, 1117; d) M. Barbero, S. Cadamuro and S. Dughera, Synthesis, 2008, 3, 474; e) M. Barbero, S. Cadamuro and S. Dughera, Eur. J. Org. Chem., 2014, 598; f) M. Barbero, S. Cadamuro and S. Dughera, Tetrahedron, 2014, 70, 8010; g) M. Barbero,S. Cadamuro, S. Dughera and C. Giaveno, Eur. J. Org. Chem., 2006, 4884; h) M. Barbero, S. Cadamuro, S. Dughera and G. Ghigo, Eur. J. Org. Chem., 2008, 862.

15 D. V. Patil, H. Yun and S. Shin, Adv. Synth. Catal. 2015, 357, 2622.

16 P. S. J. Canning, H. Maskhill, K. McCrudden and B. Sexton, Bull. Chem. Soc. Jpn., 2002, 75, 789.

17 D. F. DeTar and T. Kosuge, J. Am. Chem. Soc., 1958, 80, 6072.

18 a) M. Barbero, I. Degani, S. Dughera and R. Fochi, J. Org. Chem., 1999, 64, 3448; b) M. Barbero, S. Cadamuro and S. Dughera, Org. Biomol. Chem., 2016, 14, 1437.

19 a) R. F. Heck and J. P. Nolley, Jr., J. Org. Chem., 1972, 37, 2320; b) T. Mizoroki, K. Mori and A. Ozaki, Bull. Chem. Soc. Jpn., 1971, 44, 581.

20 A. Roe, Org. React., 1949, 5, 193. 